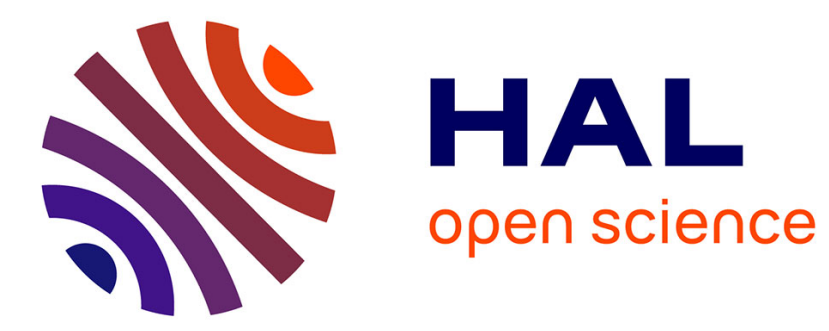

\title{
Radius of gyration of a polyion in salt free polyelectrolyte solutions measured by S. A. N. S.
}

M. Nierlich, François Boué, A. Lapp, R. Oberthur

\section{To cite this version:}

M. Nierlich, François Boué, A. Lapp, R. Oberthur. Radius of gyration of a polyion in salt free polyelectrolyte solutions measured by S. A. N. S.. Journal de Physique, 1985, 46 (4), pp.649-655. 10.1051/jphys:01985004604064900 . jpa-00210005

\section{HAL Id: jpa-00210005 https://hal.science/jpa-00210005}

Submitted on 1 Jan 1985

HAL is a multi-disciplinary open access archive for the deposit and dissemination of scientific research documents, whether they are published or not. The documents may come from teaching and research institutions in France or abroad, or from public or private research centers.
L'archive ouverte pluridisciplinaire HAL, est destinée au dépôt et à la diffusion de documents scientifiques de niveau recherche, publiés ou non, émanant des établissements d'enseignement et de recherche français ou étrangers, des laboratoires publics ou privés. 
Classification

Physics Abstracts

$61.25 \mathrm{H}-61.40 \mathrm{~K}$

\title{
Radius of gyration of a polyion in salt free polyelectrolyte solutions measured by S.A.N.S.
}

\author{
M. Nierlich, F. Boué, A. Lapp \\ L.L.B., CEN-Saclay (*), 91191 Gif-sur-Yvette Cedex, France \\ and R. Oberthur \\ I.L.L., 156 X, Centre de Tri, 38042 Grenoble Cedex, France
}

(Reçu le 29 mai 1984, révisé le 16 novembre, accepté le 6 décembre 1984)

\begin{abstract}
Résumé. - On a étudié des solutions de polyélectrolytes(NaPSS) en absence de sel ajouté. La diffusion de neutrons aux petits angles a permis de mesurer le rayon de giration $\left(R_{\mathrm{g}}\right)$ du polyion grâce au marquage spécifique (deutération) de chaînes associé à une méthode d'extrapolation qui permettent d'extraire le facteur de forme de la fonction de corrélation totale. En supposant que le modèle de chaîne à longueur de persistance tient compte de la flexibilité locale du polyion, on a extrait des valeurs de la longueur de persistance $b_{\mathrm{t}}$ à partir de $R_{\mathrm{g}}: R_{\mathrm{g}}$ et $b_{\mathrm{t}}$ décroissent quand la concentration en polyions augmente. On distingue deux domaines de concentration : à faible concentration, $R_{\mathrm{g}} c_{\mathrm{p}}^{-1 / 2}$ et $b_{\mathrm{t}} c_{\mathrm{p}}^{-1}$ et à forte concentration, $R_{\mathrm{g}} c_{\mathrm{p}}^{-1 / 4}$ et $b_{\mathrm{t}} c_{\mathrm{p}}^{-1 / 2}$. Le calcul de Le Bret pour la contribution électrostatique à la longueur de persistance décrit bien ces deux régimes.
\end{abstract}

\begin{abstract}
In this paper measurements of the radius of gyration of a polyion in salt free semi-dilute polyelectrolyte solutions are presented. We have used neutron scattering to extract the form factor of a single polyelectrolyte chain from the total correlation function by using a specific labelling associated with an extrapolation method. Assuming that the wormlike chain model takes into account the local flexibility of the chain due to electrostatic interactions along the chain, we have extracted, from the radii of gyration, values for the persistence length $b_{\mathrm{t}}$. Both $R_{\mathrm{g}}$ and $b_{\mathrm{t}}$ decrease with increasing polyion concentration, $c_{\mathrm{p}}$. We can distinguish two concentration régimes : at low concentration, $R_{\mathrm{g}}$ decreases as $c_{\mathrm{p}}^{-1 / 2}$ and $b_{\mathrm{t}}$ as $c_{\mathrm{p}}^{-1}$ and at high concentration $R_{\mathrm{g}}$ decreases as $c_{\mathrm{p}}^{-1 / 4}$ and $b_{\mathrm{t}}$ as $c_{\mathrm{p}}^{-1 / 2}$.

These two régimes for the variation of $b_{\mathrm{t}}$ with $c_{\mathrm{p}}$ are well described by a calculation of Le Bret for the electrostatic contribution to the persistence length of the polyion.
\end{abstract}

\section{Introduction.}

In solutions of polyelectrolytes, made from linear flexible polymers, an essential parameter is the polymer chain rigidity which is strongly influenced by the ionic strength and in particular by the polyelectrolyte concentration [1]. Electrostatic repulsions between charges along the chain will affect the local flexibility of the polyelectrolyte and will tend to increase the global size of the polyion. This global size may be estimated by the measurement of the mean square radius of gyration. The aim of this paper is to report such measurements obtained by small angle neutron scattering on salt free polyelectrolyte solutions. The only variable quantity is the concentration of the

(*) Laboratoire commun CEA-C.N.R.S. polyions, $c_{\mathrm{p}}$ (in moles of monomer units per liter) and we study the variation of the radius of gyration of the polyion with $c_{\mathrm{p}}$.

In salt free and dilute solution, the polyions are assumed to be stretched by electrostatic repulsion. The concentration $c^{*}$ (equal to $M / R_{\mathrm{g}}^{3}$ where $M$ and $R_{\mathrm{g}}$ are the molecular weight and the radius of gyration of the polyion) which defines the boundary between the dilute and the semi-dilute regimes is very low $[2,3]:$ it is then difficult to reach the dilute regime using neutron scattering and we work with semidilute solutions. In that case, the total monomer correlation function $S_{\mathrm{T}}(q)$ reflects the effect of the internal structure of the polyion $S_{1}(q)$ as well as the effect of the interchain correlations $S_{2}(q)$. Neutron scattering is then a privileged tool to observe one polyion among the others $[3,4]:$ a specific labelling 
(deuteration for neutron scattering) associated with an extrapolation method allows these two contributions to be separated. This method was already described in reference [3], and in reference [5] in a detailed manner. Here, we recall it briefly. We work at a fixed concentration of a mixture of deuterated (sodium polystyrene sulfonate : $\mathrm{NaPSS}_{\mathrm{D}}$ ) and hydrogenated $\left(\mathrm{NaPSS}_{\mathrm{H}}\right)$ polymer in solution in a mixture of $x_{\mathrm{D}} \mathrm{D}_{2} \mathrm{O},\left(1-x_{\mathrm{D}}\right) \mathrm{H}_{2} \mathrm{O}, x_{\mathrm{D}}$ being the mole fraction $\mathrm{D}_{2} \mathrm{O}$ necessary to match the scattering length density of the hydrogenated chains. In that case, the total monomer correlation function is :

$$
S_{\mathrm{T}}(q)=Y_{\mathrm{D}} S_{1}(q)+Y_{\mathrm{D}}^{2} S_{2}(q) .
$$

$Y_{\mathrm{D}}$ being the monomer fraction of labelled chains. The extrapolation of $S_{\mathrm{T}}(q) / Y_{\mathrm{D}}$ to zero mole fraction of labelled chains, at fixed total monomer concentration $c_{\mathrm{p}}$ of the polyelectrolyte, leads to $S_{1}(q) . S_{2}(q)$ is given by the slope of these extrapolations. From $S_{1}(q)$, we can obtain, according to the $q$ range, either the radius of gyration of the polyion or additional conformation parameters [5]. In reference [3], measurements of the radius of gyration of a low molecular weight NaPSS have been reported and for the first time tested the method but the experimental conditions were not adequate : in particular, the mole fraction of $\mathrm{D}_{2} \mathrm{O}$ used in this first experiment did not match the hydrogenated polymer. We have now corrected this error and made new experiments with a similar molecular weight of NaPSS over a large range polyion concentration. In addition, assuming the wormlike chain model for the polyelectrolyte chain, we extract, from $R_{\mathrm{g}}$, a persistence length $b_{\mathrm{t}}$ which reflects the flexibility of the chain at small distances : the variation of $b_{\mathrm{t}}$ with $c_{\mathrm{p}}$ is then obtained.

\section{Experiments.}

2.1 SAmples. - The characteristics of the samples are summarized in table I.

Sodium polystyrene sulfonate has been prepared by one of us at the C.R.M. in Strasbourg by sulfonation of polystyrene using the method of Vink [6] : this method leads to a fully charged chain. Molecular weight distributions have been measured first by GPC in THF on the neutral polymer [7], then by aqueous GPC on the sulfonated polymer. Their polydispersity is characterized by the ratio $M_{\mathrm{w}} / M_{\mathrm{n}}$ where $M_{\mathrm{w}}$ is the weight average molecular weight and $M_{\mathrm{n}}$ the number average molecular weight. The polydispersities after sulfonation are higher than those of the neutral polymer.

After freeze-drying, chemical analysis shows that some water always remains : the given concentrations are corrected for this amount of residual water. The range of the total concentration $c_{\mathrm{p}}$ extends between $0.0817 \mathrm{M}$ and $0.563 \mathrm{M}(1 \mathrm{M}=1 \mathrm{~mole} / \mathrm{liter})$.

2.2 Determination of $x_{\mathrm{D}}$. - Solutions are made from a mixture of $\mathrm{NaPSS}_{\mathrm{H}}$ and $\mathrm{NaPSS}_{\mathrm{D}}$ in a mixture of $\mathrm{D}_{2} \mathrm{O}$ and $\mathrm{H}_{2} \mathrm{O}$. The suitable value of $x_{\mathrm{D}}$ for the extinction of the scattering of the hydrogenated chain is $0.485 \pm 0.005$. It is obtained by the relation

$$
x_{\mathrm{D}}=\frac{\sum \frac{b_{i}}{V^{2}}-\tilde{\rho} \mathrm{H}_{2} \mathrm{O}}{\tilde{\rho} \mathrm{D}_{2} \mathrm{O}-\tilde{\rho} \mathrm{H}_{2} \mathrm{O}}
$$

where $\sum b_{i}=50.89 \mathrm{fm}$ is the total scattering length of the NaPSS monomer $\left(\mathrm{C}_{8} \mathrm{H}_{7} \mathrm{SO}_{3} \mathrm{Na}\right)$;

$V_{2}=108.2 \mathrm{~cm}^{3} / \mathrm{mole}$ is the partial molar volume of the NaPSS monomer [8];

$\tilde{\rho} \mathrm{H}_{2} \mathrm{O}=-0.56 \times 10^{10} \mathrm{~cm}^{-2}$ and $\tilde{\rho} \mathrm{D}_{2} \mathrm{O}=$ $6.36 \times 10^{10} \mathrm{~cm}^{-2}$ are the scattering length densities of light and heavy water at $25^{\circ} \mathrm{C}$. An experimental measurement of $x_{D}$ has been made for a slightly different polystyrene sulfonate during the experiment reported in reference [5] $\vdots$ the obtained value is 0.487 . We have finally chosen for the sample used here the lower value of $x_{\mathrm{D}}=0.485 \pm 0.05$ which seems more reasonable due to the uncertainty in the degree of sulfonation.

Table I. - Characteristics of the sodium polystyrene sulfonates. The characteristics of hydrogenated and deuterated parent polystyrene used for the sulfonation are described in reference [7].

\begin{tabular}{|l|c|c|}
\hline \multirow{2}{*}{ Origin } & Deuterated & Hydrogenated \\
\cline { 2 - 3 } & C.R.M. Strasbourg & C.R.M. Strasbourg \\
\hline Polydispersity of parent polystyrene & $\frac{M_{\mathrm{w}}}{M_{\mathrm{n}}}=1.10 \pm 0.05$ & $\frac{M_{\mathrm{w}}}{M_{\mathrm{n}}}=1.05 \pm 0.05$ \\
Molecular weight of NaPSS & 26000 & 30200 \\
Rate of sulfonation & $98 \%$ & $95 \%$ \\
Water content after freeze drying(w/w) & $12.8 \% \pm 3 \%$ & $10.9 \% \pm 3 \%$ \\
Polydispersity after sulfonation & 1.15 & 1.13 \\
\hline
\end{tabular}


2. 3 Neutron measurements. - The S.A.N.S. instrument used is D 11 at the I.L.L. in Grenoble : the sample detector distance was $10.6 \mathrm{~m}$ with an incident wavelength of $9.90 \AA$ which gave a $q$ range from $4.43 \times 10^{-3}$ to $2.27 \times 10^{-2} \AA^{-1}$.

2.4 Extrapolation of $S_{1}(q)$ FROM $S_{\mathrm{T}}\left(q, Y_{\mathrm{D}}\right)$. We use formula (1) to plot $S_{\mathrm{T}}\left(q, Y_{\mathrm{D}}\right) / Y_{\mathrm{D}}$ as a function of $Y_{D}$ for each value of $q$. The curves must appear as straight line which was always the case using four values of $Y_{\mathrm{D}}$. Representative extrapolations are shown in figure 1 for two values of $q$ and $c_{\mathrm{p}}$.

\section{Measure of the radius of gyration.}

The form factor $S_{1}(q)$ is extracted from the total scattering function $S_{\mathrm{T}}(q)$ using equation $(1): S_{1}(q)$ contains all information on the dimension of an isolated polyion in solution.

First, we use the classical method to extract the radius of gyration from the form factor $S_{1}(q)$, the Zimm plot :

$$
S_{1}^{-1}(q)=1+q^{2} R_{\mathrm{g}}^{2} / 3 .
$$

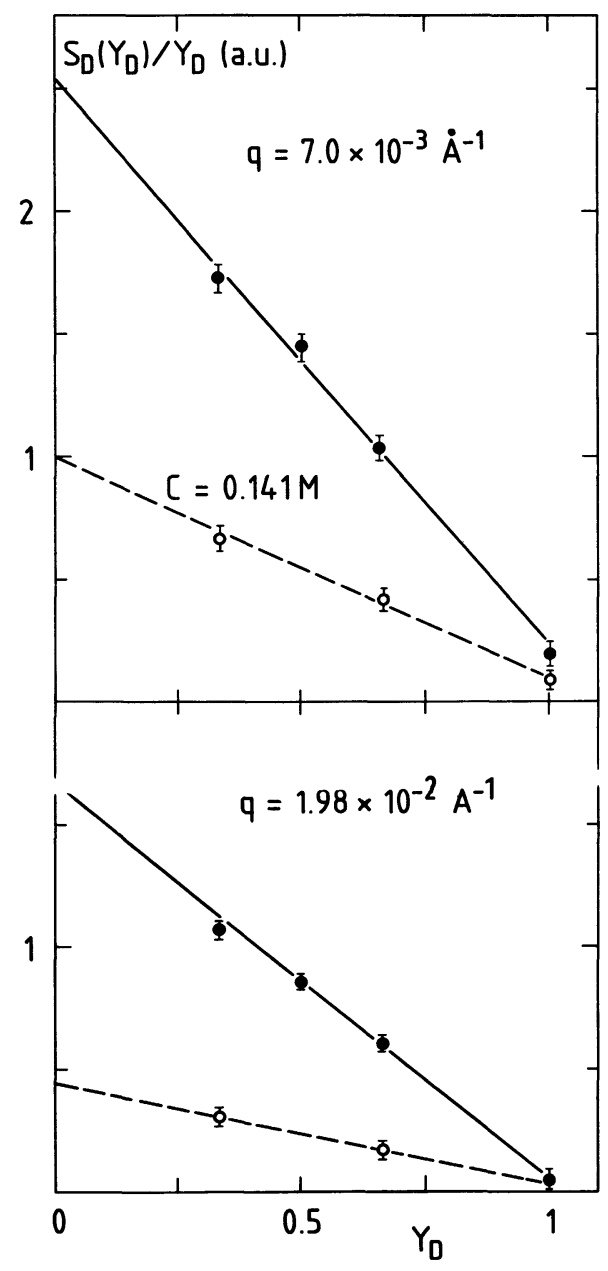

Fig. 1. - Scattering functions $S_{\mathrm{D}}\left(Y_{\mathrm{D}}, q\right) / Y_{\mathrm{D}}$ as a function of $Y_{\mathrm{D}}$ for two $q$ values, for $c_{\mathrm{p}}=0.563 \mathrm{M}$ (ฐ) and $c_{\mathrm{p}}=$ $0.141 \mathrm{M}$ (호). The extrapolation of the straight line to $Y_{\mathrm{D}}=0$ yields $S_{1}(q)$.
The obtained values of the radius of gyration are tabulated in the first column of table II. However, these values of $R_{\mathrm{g}}$ greatly depend on the range over which the extrapolation has been performed : the Zimm plot representation gives a good linearization of the scattering function only for Gaussian coils with a Schulz-distribution of their molecular weight and a polydispersity $M_{\mathrm{w}} / M_{\mathrm{n}}=2$. If $M_{\mathrm{w}} / M_{\mathrm{n}}$ approaches 1 , then more and more deviations occur from linearity, especially if $q R_{\mathrm{g}}$ exceeds $1[9,11]$. With the obtained values of $R_{\mathrm{g}}$ and the experimental $q$ range, however, $q R_{\mathrm{g}}$ extends between 0.7 and 2.1 for all the studied concentrations : hence, in this case a Zimm plot is not recommended and another plot which takes the conformation of the polyion into account must be used to obtain a better estimate of $R_{\mathrm{g}}$.

Because the conformation of the polyion which changes with the concentration of polyions is yet unknown, we can consider only the two extreme conformations, a rod at low concentration and a Gaussian coil at high concentration, to extract $R_{\mathrm{g}}$.

In both cases, for monodisperse or only slightly polydisperse systems, the Berry plot is more suitable for the linearization of the scattering curve in the range $q R_{\mathrm{g}}, 0.7-2[9] . S_{1}^{-1 / 2}(q)$ versus $q^{2}$ gives a straight line of slope $R_{\mathrm{g}}$.

$$
S_{1}^{-1 / 2}(q)=1+q^{2} R_{\mathrm{g}}^{2} / 6 .
$$

Figure 2 shows the behaviour of $S_{1}^{-1 / 2}(q)$ for all the samples.

We remark that the first five points fall well below the straight line which well fits all the following points. A straight line including these first five points leads to a $R_{\mathrm{g}}>R_{\text {grod }}=93 \AA$ (see Table II), which is

Table II. - Radius of gyration obtained from :

- The Zimm plot : $S_{1}^{-1}(q)=1+\frac{q^{2} R_{\mathrm{g}}^{2}}{3}$.

\begin{tabular}{|c|c|c|}
\hline $\begin{array}{l}C \\
\mathbf{M}\end{array}$ & $\begin{array}{l}R_{\mathrm{g}} \AA \\
\text { Zimm plot }\end{array}$ & $\begin{array}{l}R_{\mathrm{g}} \quad \AA \\
\text { Berry plot }\end{array}$ \\
\hline $\begin{array}{l}0.0817 \\
0.123 \\
0.208 \\
0.338 \\
0.404 \\
0.484 \\
0.563\end{array}$ & $\begin{array}{l}94 \pm 6 \\
77 \pm 6 \\
62 \pm 5 \\
61 \pm 3 \\
63 \pm 2 \\
55 \pm 3 \\
56 \pm 3\end{array}$ & $\begin{array}{l}81 \pm 5 \\
65 \pm 5 \\
57 \pm 3 \\
55 \pm 4 \\
54 \pm 3 \\
53 \pm 3 \\
52 \pm 3\end{array}$ \\
\hline
\end{tabular}

- The Berry plot $S_{1}(q)^{-1 / 2}=1+\frac{q^{2} R_{\mathrm{g}}^{2}}{6}$.

$R_{\text {grod }}=93 \AA$.

$R_{\mathrm{g} \theta}^{\mathrm{grod}}=34 \AA$. 


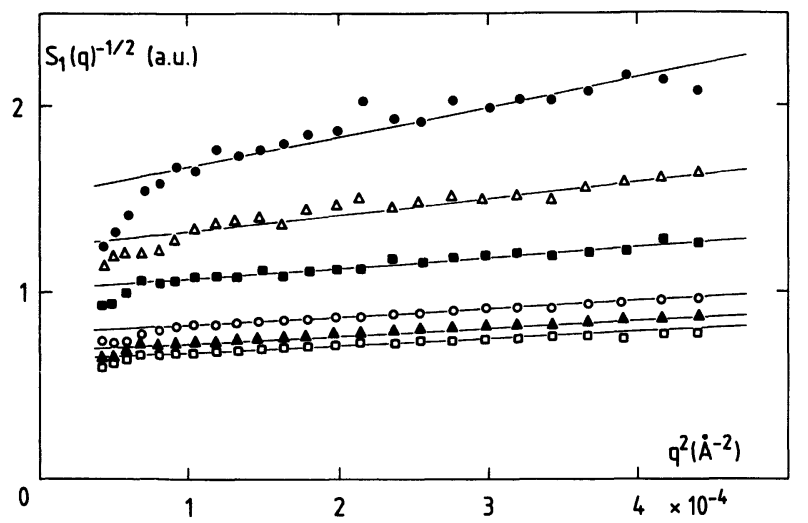

Fig. 2. - Berry plot of $S_{1}(q)$ for all the samples : $c_{\mathrm{p}}=$ $0.0817 \mathrm{M} ; \Delta c_{\mathrm{p}}=0.123 \mathrm{M} ; \square c_{\mathrm{p}}=0.208 \mathrm{M} ; \circ c_{\mathrm{p}}=$ $0.338 \mathrm{M} ; \Delta c_{\mathrm{p}}=0.404 \mathrm{M} ; \square c_{\mathrm{p}}=0.484 \mathrm{M}$. The units for $S_{1}(q)$ are arbitrary.

obviously unrealistic. We believe that these points correspond to an overscattering at small angles : this has always been observed in all our polyelectrolytes (see for example Fig. 2 of Ref. [2]). We think that this scattering does not depend on the purity of the solution but mainly on the chemical preparation of the sample : up to now, we did not succeed in eliminating it.

The new radii of gyration are reported in the second column of table II.

We can see in there that :

- The Zimm plot yields higher values and the Berry plot lower values.

- The gap between these two sets of $R_{\mathrm{g}}$ which is large for the lower concentrations $\left(13 \%\right.$ for $\left.c_{\mathrm{p}}=0.087\right)$ is reduced for the higher concentrations $(6 \%$ for $\left.c_{\mathrm{p}}=0.563\right)$. This is well explained by the decrease of $R_{\mathrm{g}}$ with $c_{\mathrm{p}}$ : at high $c_{\mathrm{p}}, R_{\mathrm{g}}$ is smaller and $\left(q R_{\mathrm{g}}\right)_{\max }$ is of the order of 1 and in that case, the results from the two plots, Zimm and Berry, are very similar [9]. Since at high concentrations the two values are equal to within the uncertainty of the two plots and since at low concentrations, the Berry plot fits better the quasi rod conformation, we decide to discuss the Berry plot values.

\section{Variation of $\boldsymbol{R}_{\mathrm{g}}$ with $\boldsymbol{c}_{\mathrm{p}}$.}

Figure 3 shows the variation of $R_{\mathrm{g}}$ with the concentration of polyions : it shows a continuous decay as $c_{\mathrm{p}}$ increases. At low concentration, an important decrease of $R_{\mathrm{g}}$ is observed with increasing concentration whereas at high concentration, this decrease is slowed down. To compare these experimental values with the two limiting cases, we can calculate :

- First, the radius of gyration of the totally stretched chain of length $L=N p$ where $N$ and $p$ are the number and the repeat distance of monomers along the chain. We take $R_{\mathrm{g}}=L / \sqrt{12}$ which gives with $p=2.22 \AA$ the repeat distance of an isotactic

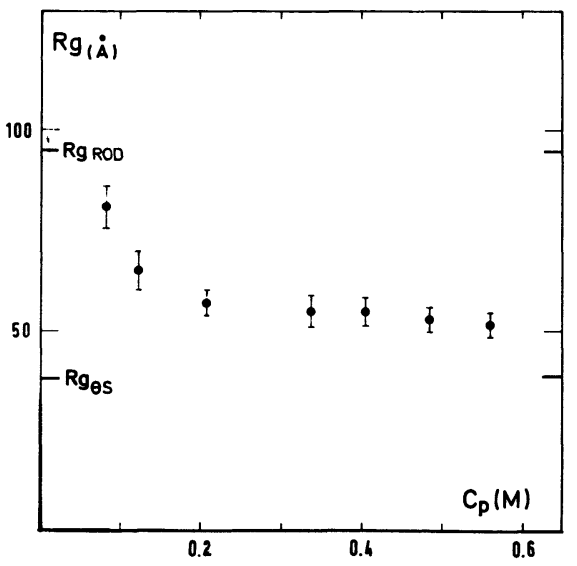

Fig. 3. - Variation of the radius of gyration with the concentration of polyions. The radius of gyration is extracted from the Berry plot : $S_{1}^{-1 / 2}(q)$ versus $q^{2}$.

polystyrene chain [20], and $N=122, L=271 \AA$ and $R_{\mathrm{g}}=78 \AA$.

- Second, the radius of gyration of the parent polystyrene in theta solvent which using the expression $\left\langle R_{\mathrm{g}}^{2}\right\rangle_{z}^{1 / 2}=0.27 M_{\mathrm{w}}^{0.506}[10]$, gives $R_{\mathrm{g}}=32 \AA$.

Introducing the polydispersity $M_{\mathrm{w}} / M_{\mathrm{n}}=1+U=$ 1.15 , we obtain for the rod [11]

$\left\langle R_{\mathrm{g}}^{2}\right\rangle_{z}^{1 / 2}=\left[\frac{(1+3 U)(1+2 U)}{(1+U)^{2}}\right]^{1 / 2} \frac{L}{\sqrt{12}}=93 \AA$

and for the coil

$$
\left\langle R_{\mathrm{g}}^{2}\right\rangle^{1 / 2}=\left[\frac{1+2 U}{1+U}\right]^{1 / 2}\left\langle R_{\mathrm{g}}^{2}\right\rangle^{1 / 2}=34 \AA .
$$

A double logarithmic plot of $R_{\mathrm{g}}$ as a function of $c_{\mathrm{p}}$ allows two concentration regimes to be distinguished (Fig. 4) :

- In a low concentration regime, the first three points appear close to a line of slope $0.48 \pm 0.05$. The behaviour is then :

$$
R_{\mathrm{g}} \propto c_{\mathrm{p}}^{-1 / 2} .
$$

For the lowest studied concentration of this regime the polyion is very extended but not totally stretched :

$$
R_{\mathrm{g}} / R_{\mathrm{grod}}=0.87 \text {. }
$$

This ratio could approach one at lower concentrations or if we have slightly overestimated $R_{\text {grod }}$ (the actual chain conformation has to be taken into account).

- In a high concentration regime another straight line could be plotted of slope $0.20 \pm 0.08$. The decay of $R_{\mathrm{g}}$ with the increase of $c_{\mathrm{p}}$ can be roughly taken as :

$$
R_{\mathrm{g}} \propto c_{\mathrm{p}}^{-1 / 4} .
$$

Let us remark that for the highest studied concentration, the overall size of the corresponding neutral polymer is not yet reached $: R_{\mathrm{g}} / R_{\text {gneutral }}=1.53$. 


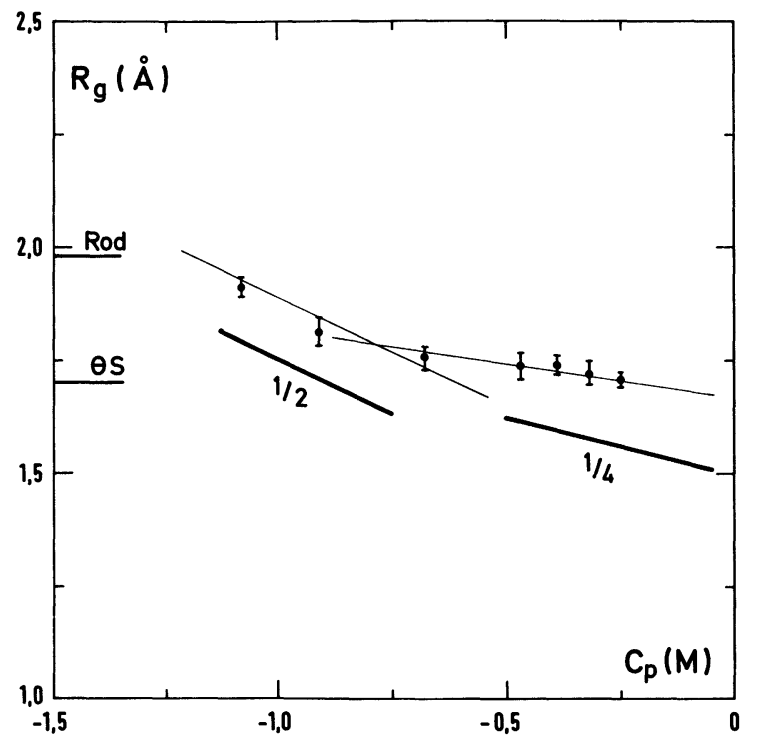

Fig. 4. - Double logarithmic plot of $R_{\mathrm{g}}$ versus $c_{\mathrm{p}}$.

\section{Discussion.}

The wormlike chain description.

These results show that the two possible extreme conformations of the polyion, rod and Gaussian coil conformation of the $\theta$-state of polystyrene $(\lambda)$ have not been observed and we are dealing only with intermediate conformations of a polyion having a more or less local stiffness. Such a chain is classically described by the wormlike chain model which allows a continuous transition from rod to Gaussian coil [12]. This model requires two parameters for its characterization, the persistence length $b_{\mathrm{t}}$ and the contour length $L$. When $L / b_{\mathrm{t}}$ is small, the chain is very stiff and rodlike, and when $L / b_{t}$ is large, the chain is Gaussian.

The radius of gyration of such a chain is given by [13] :

$$
\left\langle R_{\mathrm{g}}^{2}\right\rangle=b_{\mathrm{t}}^{2}\left[\frac{x}{3}-1+\frac{2}{x}-\frac{2}{x^{2}}(1-\exp (-x))\right]
$$

with $x=L / b_{\text {r }}$.

For $L / b_{\mathrm{t}} \ll 1$, equation (7) leads to

$$
R_{\mathrm{g}}^{2}=\frac{L^{2}}{12}
$$

which is the radius of gyration of a rod of length $L$.

For $L / b_{t} \gg 1$, equation (7) leads to

$$
R_{\mathrm{g}}^{2}=b_{\mathrm{t}} L / 3
$$

which is the radius of gyration of a Gaussian coil.

Equations (8) and (9) are the extreme conditions for the dimension of the polyion.

Equation (7) is only valid for monodisperse samples and appropriate corrections have to be made for polydisperse samples [11]. A molecular weight distribution, approximated by the continuous Schulzdistribution, leads to

$$
\begin{aligned}
\left\langle R_{\mathrm{g}}^{2}\right\rangle_{\mathrm{z}}\left(M_{\mathrm{w}}, U\right)=\frac{1+2 U}{1+U} \frac{L b_{\mathrm{t}}}{3}\left\{1-\frac{1+U}{1+2 U} \frac{3 b_{\mathrm{t}}}{L}\left(1-\frac{2 b_{\mathrm{t}}}{L}\right)-\right. & \\
& \left.-\frac{(1+U)^{2}}{1+2 U} \frac{6 b_{\mathrm{t}}^{3}}{L^{3}}\left[1-\left(1+\frac{U}{1+U} \frac{L}{b_{\mathrm{t}}}\right)^{-1 / U}\right]\right\}
\end{aligned}
$$

where $U=M_{\mathrm{w}} / M_{\mathrm{n}}-1$, and $\left\langle R_{\mathrm{g}}^{2}\right\rangle_{z}$ is the $z$-average of the mean square radius of gyration as obtained from the scattering data of polydisperse samples.

According to equation (10), $R_{\mathrm{g}}$ depends on three parameters, $b_{t}, L$ and $U$. $U$ can be obtained from table I and two unknown parameters remain. With this single experiment, we have no means to know exactly the value of $L$ but a maximum value can be evaluated. The NaPSS molecule of molecular weight 26000 consists of $N=122$ monomers with a repeat distance of $p=2.5 \AA$ (if the polymer is in a $l_{1}$-helix (Zig-Zag) conformation [20]), so the maximum contour length is $L=305 \AA$.

Table III presents, in the first two columns, a comparison of values of the persistence length $b_{t}$ obtained with formula (7), $U=0$, and formula (10), $U=0.15$. The effect of the variation of $L$ is shown in the last two columns with $p=2.5 \AA, L=305 \AA$ and $p=2.22 \AA, L=271 \AA$.
It appears, from comparison of columns 1 and 2, that the value of $b_{\mathrm{t}}$ strongly depends on the polydispersity. We thus want to stress that the knowledge of the polydispersity is absolutely necessary to extract the persistence length, especially for the rod limit. It also appears that the extraction of $b_{\mathrm{t}}$ is very sensitive to both the absolute value of $R_{\mathrm{g}}$ and the error on $R_{\mathrm{g}}$. At low concentrations, $R_{\mathrm{g}}$ is close to the value of the radius of gyration of the rod for which $b_{t}$ must be infinite and a weak variation of $R_{\mathrm{g}}$ in this range leads to a large variation of $b_{\mathrm{t}}$ : for example for $c=0.0817$, the error in $R_{\mathrm{g}}$ is $10 \%$ but the error in $b_{\mathrm{t}}$ is $50 \%$.

The variation of $b_{t}$ with the concentration of polyions is shown in figure 5, for the two sets of values corresponding to $U=0.15$. The plots $b_{\mathrm{t}}$ versus $c_{\mathrm{p}}^{-1 / 2}$ appear linear for the higher concentration and at an infinite concentration these two straight lines converge to one value of $b_{\mathrm{t}}$ which is the persistence 
Table III. - Persistence length as a function of polyelectrolyte concentration extracted from $R_{\mathrm{g}}$ for various assumptions. The first two columns of $b_{\mathrm{t}}$ show the influence of the polydispersity, the last two columns the remaining uncertainty due to the unknown contour length of the polyion.

\begin{tabular}{|c|c|c|c|}
\hline$c_{\mathbf{p}}$ & $\begin{aligned} & b_{\mathrm{t}} \\
\AA & \AA \\
L= & 305 \AA \\
U= & 0\end{aligned}$ & $\begin{aligned} & b_{\mathrm{t}} \\
\AA & \AA \\
L= & 305 \AA \\
U= & 0.15\end{aligned}$ & $\begin{aligned} & b_{\mathrm{t}} \\
L= & 271 \AA \\
U= & 0.15\end{aligned}$ \\
\hline 0.0817 & $594+404$ & $139+42$ & $318+160$ \\
\hline 0.123 & $85 \pm 26$ & $59 \pm 15$ & $80 \pm 22$ \\
\hline 0.208 & $51 \pm 10$ & $39 \pm 6$ & $49 \pm 9$ \\
\hline 0.338 & $46 \pm 10$ & $35 \pm 7$ & $44 \pm 10$ \\
\hline 0.404 & $43 \pm 7$ & $33 \pm 5$ & $41 \pm 7$ \\
\hline 0.484 & $41 \pm 7$ & $32 \pm 5$ & $39 \pm 6$ \\
\hline 0.563 & $39 \pm 6$ & $30 \pm 5$ & $37 \pm 6$ \\
\hline
\end{tabular}

length of the neutral polymer : we found $12 \AA$, in agreement with different determinations $[5,14]$. At low concentrations, a pronounced deviation from this law $b_{\mathrm{t}} \propto c_{\mathrm{p}}^{-1 / 2}$ is observed : a $\log \log$ plot of $b_{\mathrm{t}}$ as a function of $c_{\mathrm{p}}$ indicates a concentration dependence close to $c_{\mathrm{p}}^{-1}$.

In conclusion, these data indicate two clear features :

- at low concentrations :

$$
b_{\mathrm{t}} \propto c_{\mathrm{p}}^{-1}
$$

- and at high concentrations :

$$
b_{\mathrm{t}} \propto c_{\mathrm{p}}^{-1 / 2} \text {. }
$$

During the last few years, theoretical estimates of the persistence length have been given. The total persistence length $b_{\mathrm{t}}$ which gives some idea of the local stiffness of the polyion is the sum of two contributions : $b_{\mathrm{p}}$ the intrinsic persistence length of the neutral backbone and $b_{\mathrm{e}}$ the electrostatic contribution arising from the interactions between charges along the flexible backbone : $b_{\mathrm{t}}=b_{\mathrm{p}}+b_{\mathrm{e}}$.

The electrostatic contribution to the persistence length $b_{\mathrm{e}}$ has been calculated by several workers $[15,16,18,19]$.

T. Odijk [15] and J. Skolnick and M. Fixman [16], assuming that the charges interact through a DebyeHückel potential, have found :

$$
b_{\mathrm{e}}=\frac{1}{12} Q N^{2} h(y)
$$

where $Q$ is the Bjerrum length $\left(Q=\left(e^{2}\right) / \varepsilon_{0} k T=\right.$ $7.13 \AA$ in water), $y=K L$ with $L$ the contour length of the polyion and $K^{-1}$ the Debye-Hückel screening length related to the concentration through the relation :

$$
K^{2}=8 \pi Q c
$$

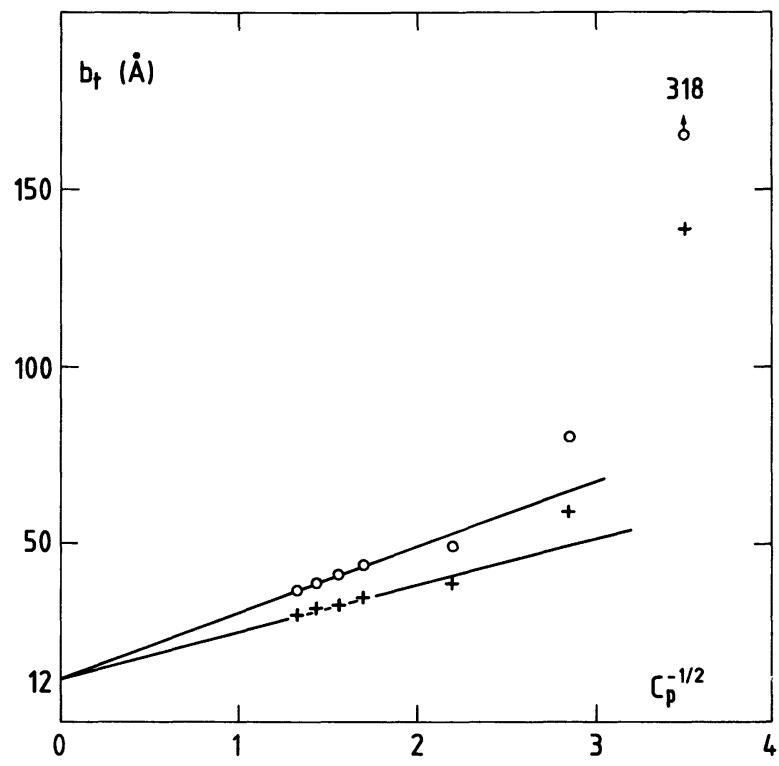

Fig. 5. - Variation of the total persistence length $b_{\text {, }}$ with the concentration of polyions. The values of $b_{t}$ are extracted from $R_{\mathrm{g}}$ using equation (10) with :

$$
\begin{array}{ll}
+U=0.15 \text { and } L=305 \AA \\
\bigcirc U=0.15 \text { and } L=271 \AA .
\end{array}
$$

where $c$ is the concentration of the non condensed counter ions.

In the case of the rod limit

$$
h(y)=\mathrm{e}^{-y}\left(y^{-1}+5 y^{-2}+8 y^{-3}\right)+3 y^{-2}-8 y^{-3} \text {. }
$$

If the two following conditions are obeyed :

$-K b_{\mathrm{t}} \gg 1$, which is true for polyelectrolytes near the rod limit or at least for polyelectrolytes having a high intrinsic stiffness. [17]

- The counter ion condensation model applies

Formula (11) gives

$$
b_{\mathrm{e}}=\frac{1}{4 K^{2} Q} .
$$

Then, the persistence length $b_{\mathrm{e}}$, depends on the concentration through $K^{2}$ : relations (14) and (12) give a $c_{\mathbf{p}}^{-1}$ dependence for $b_{\mathrm{e}}$.

This $c_{\mathbf{p}}^{-1}$ dependence is found experimentally for the lower concentrations but a departure from this law appears for the higher concentrations. This deviation could be related to the fact that for this kind of flexible polyelectrolyte having a small intrinsic stiffness, the condition $K b_{\mathrm{t}} \gg 1$ is not fully satisfied (for the smallest concentration $K b_{\mathrm{t}} \sim 12$ and for the highest $\left.K b_{\mathrm{t}} \sim 4\right)$. In addition, the values of $b_{\mathrm{e}}$ calculated with equation (14) are smaller than those found experimentally (Fig. 6). As the condition $K b_{\mathrm{t}}>1$ is not fulfilled for these concentrations, formula (11) will be perhaps more suitable for calculating $b_{\mathrm{e}}$. 


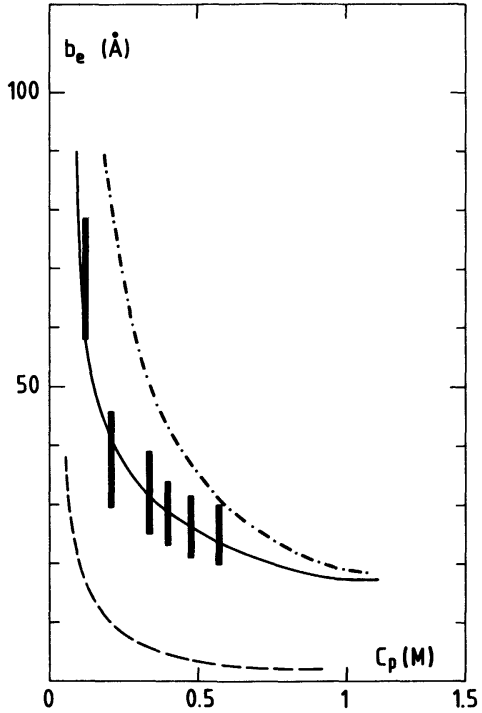

Fig. 6. - Calculated values of the electrostatic persistence length by Le Bret (-) and Odijk $\left[(--) b_{\mathrm{e}}=1 / 4 K^{2} Q\right.$ $(-\cdots) b_{\mathrm{e}}=(1 / 12) Q N^{2} h(y)$ with $N=122$ and $\left.L=271 \AA\right]$ are compared to experimental values $b_{\mathrm{e}}=b_{\mathrm{t}}-b_{\mathrm{p}}$ with $b_{\mathrm{p}}=12 \AA$.

These new values are reported on figure 6 where one can see that they also disagree with experimental values.

More recently, Fixman [18] and Le Bret [19] have performed new calculations of $b_{\mathrm{e}}$. Le Bret has integrated the complete Poisson-Boltzmann equation for a toroid. The results cannot be put into a simple analytical form but numerical calculations made by Le Bret (reported in Fig. 4 of Ref. [5]) lead to two concentration régimes for the variation of $b_{\mathrm{e}}$ with $c_{\mathrm{p}}$ : at low concentration $b_{\mathrm{e}} \propto c_{\mathrm{p}}^{-1}$ and at high concentration $b_{\mathrm{e}} \propto c_{\mathrm{p}}^{-1 / 2}$ (for more details see Ref. [19] and [5]).

First, these two concentration régimes agree with the experimental determination and, moreover, calculated and experimental values are in good agreement : this is shown in figure 6 which gives the comparison between $b_{\mathrm{e}}$ experimental, $b_{\mathrm{e} \text { Odijk }}$ and $b_{\text {e Le Bret }}$.

In reference [5], we report results concerning NaPSS of a larger molecular weight and we have extracted $b_{t}$ from a fit between the experimental curves $S_{1}(q)$ and the calculated correlations functions for a wormlike chain [21-23] : these two sets of $b_{t}$, extracted from $R_{\mathrm{g}}$ and from $S_{1}(q)$ at high $q$ are in good agreement.

\section{Acknowledgments.}

We wish to thank M. Le Bret for his helpful collaboration and especially for the calculation of the electrostatic persistence length. We are indebted to M. Rawiso, G. Jannink and G. Weill for various discussions and G. Jannink for a careful criticism of the manuscript.

\section{References}

[1] De Gennes, P. G., Scaling concepts in polymer physics, Cornell University Press. (Ithaca and London).

[2] Nierlich, M., Williams, C., Boué, F., Cotton, J. P., Daoud, M., Farnoux, B., Jannink, G., Picot, C., Moan, M., WolfF, C., Rinaudo, M., DE GenNes, P. G., J. Physique 40 (1979) 701.

[3] Williams, C., Nierlich, M., Cotton, J. P., Jannink, G., Boué, F., Daoud, M., Farnoux, B., Picot, C., De Gennes, P. G., Rinaudo, M., Moan, M., Wolff, C., J. Polym. Sci. Polym. Lett. Ed 17 (1979) 379.

[4] Axcasu, C., J. Polym. Sci. Polymer Phys. Ed. 18 (1980) 863.

[5] Nierlich, M., Boue, F., Oberthur, R., LapP, A., Submitted to J. Colloid Polym. Sci.

[6] VINK, H., Makromol. Chem. 182 (1981) 279.

[7] LaPP, A., Strazielle, C., Submitted to Makromol. Chem.

[8] Ise, N., Okubo, T., J. Amer. Chem. Soc. 90 (1968) 4527.

[9] Kirste, R. G. and Oberthur, R. C., Small Angle $X$ ray scattering, Chapter 12 Edited by $O$. Glatter and O. Kratky (Academic Press, London) 1982.
[10] Cotton, J. P., J. Physique Lett. 41 (1980) L-231.

[11] Oberthur, R., Makromol. Chem. 179 (1978) 2693.

[12] Kratky, O., Porod, G., Rec. Trav. Chem. Pays-Bas 68 (1949) 1106.

[13] Benoit, H., Doty, P., J. Phys. Chem. 57 (1953) 958.

[14] Rawiso, M., Benoit, H., Duplessix, R., Picot, C., WeILL, G., Submitted to Macromolecules.

[15] OdiJk, T., J. Polym. Sci., Polym. Phys. 15 (1977) 477.

[16] Skolnick, J. and Fixman, M., Macromol. 10 (1977) 944.

[17] Manning, G. S., J. Chem. Phys. 51 (1969) 924.

[18] Fixman, M., J. Chem. Phys. 7612 (1982) 6346.

[19] Le Bret, M., J. Chem. Phys. 7612 (1982) 6243.

[20] Birshtein, T. M., Ptitsyn, O. B., Conformations of Macromolecules (Interscience Publishers, New York) 1966 , p. 62-63.

[21] Sharp, P., Bloomfield, V. A., Biopolymers 6 (1968) 1201.

[22] Des Cloizeaux, J., Macromolecules 7 (1974) 649.

[23] Yoshizaki, T. and YamakaWA, H., Macromolecules 13 (1980) 1518. 